\title{
DESARROLLO HUMANO, EDUCACIÓN Y APRENDIZAJE
}

\author{
Ana Teresa León Sáenz' \\ Zulay Pereira Pérez ${ }^{2}$
}

Se aborda el análisis del concepto de desarrollo humano y su aplicación a la educación. Asume su contexto histórico social y lo complementa con la dimensión individual, la cual es analizada desde la perspectiva de áreas y etapas que la caracterizan, manteniendo en mente la integralidad que en todo momento presenta el desarrollo humano.

Se propone un análisis de las implicaciones y aplicaciones para la educación de los procesos básicos que se dan en cada una de las etapas del desarrollo de las personas menores de edad, con el objetivo de plantear posibles actividades que lo promuevan.
This article analizes the concept of human development and its implications in education. It considers the historical and social dimensions as well as the individual ones, the latter are considered in terms of the stages and areas, keeping in mind the wholeness that characterizes human development.

Besides, it analizes the educational implications of the basic principles that characterize human development in children and adolescents, with the objetive of establishing possible educational activities that will promote this development.

1 Profesora de la Universidad Nacional, Máster en Psicología de la Universidad Estatal de lowa. Exdirectora deł Instituto del Niño de la Universidad Nacional, Docente e investigadora de la División de Educación Básica. Exgerente Técnica del Patronato Nacional de la Infancia. Publicaciones relacionadas con psicología educativa, desarrollo del niño de 0 a 6 años y calidad en la atención a la niñez.

2 Catedrática de la Universidad Nacional. Máster en Psicología de la Universidad de Costa Rica. Excoordinadora e Investigadora del Programa de Investigación en Epistemología Genética y Educación del IIMEC, Universidad de Costa Rica. Exdirectora de la División de Educación Básica del CIDEUNA. Actualmente se desempeña como docente e investigadora en el Centro de Investigación y Docencia en Educación. Tiene publicaciones en el campo de la psicología educativa. 
El desarrollo humano como factor globalizador de muchos procesos mantiene una estrecha relación con el aprendizaje y la educación, ya que éstos últimos se constituyen en los promotores fundamentalcs que facilitan el avance del desarrollo a lo largo de la vida.

Por endc, y como parte de un trabajo sobre áreas disciplinarias del conocimiento que dan fundamento a las carreras de la División de Educación Básica del CIDE (DEB, 2001), y en respucsta a múltiples consultas y demandas de los académicos y estudiantes y como parte de la opción humanistica que ha asumido la Universidad Nacional, sc ha preparado este articulo sobre las interaccioncs que se dan cntre estos conceptos, a saber: dcsarrollo humano, educación y aprendizaje.

Sc proponen las definiciones principalcs acerca del concepto de desarrollo, sc analiza la contextualización histórica y social del desarrollo humano y sc retoman los clementos individuales más importantes en las distintas árcas en que éste se manificsta, para posteriormente analizar cl conccpto de aprendizaje y su relación con el desarrollo. Sc clabora por árcas y etapas un panorama que permitc abordar las implicacioncs pedagógicas que cl desarrollo humano tiene y que obligan a que todo(a) cducador(a) conozca los aspectos más relcvantes del desarrollo para incrementar su cfectividad y rcalización como docente.

\section{Concepto de desarrollo humano y su interacción con la educación y el aprendizaje}

En cl sentido más general, el término desarrollo ha sido asociado a factores de carácter económico y social. No obstante, dicho término ticnc otras accpciones, en especial cuando sc aborda cl tema del desarrollo humano desde lo individual. Se analizará primero la concepción macrosocial para luego considerar las definiciones de nivel personal.

El concepto de desarrollo social habitualmente ha sido asociado a ideas como crecimiento cconómico, formación de capital humano, desarrollo de recursos humanos y necesidades básicas, entre otros. Estos planteamientos priorizan el aspecto económico, por lo que el hombre como individuo, queda en un segundo término y como un medio para obtencr riqueza.

Aunque el ingreso económico cs un componentc importante para el desarrollo humano, no es en ningún modo sustituto de otros clementos tales como la libertad política, los derechos humanos, la participación, la scguridad, entre otros.

A partir de 1990, se intenta colocar cl concepto de mancra prioritaria, en el desarrollo de las potencialidades humanas para cl disfrutc de una vida íntegra y plena, constituyéndose $\mathrm{cl}$ hombre en la finalidad (PNUD, 2001). 
Este planteamiento consiste en la creación de un ambiente que permita a las personas gozar de una vida prolongada, saludable y creativa; es así, como el PNUD (citado por PNUD, 2001), define que "el propósito del desarrollo consiste en crear una atmósfera en que todos puedan aumentar su capacidad y las oportunidades puedan ampliarse para las generaciones presentes y futuras (p. 1).

Al tratar de crear un índice compuesto de desarrollo humano, se le da a los individuos la oportunidad de no aislar los diferentes aspectos de sus vidas y tener la sensación general de lo que es el bienestar.

En términos opcrativos, para el PNUD (2001) el desarrollo humano se traduce en:

- Esperanza de vida, con la cual se mide la longevidad

- Tasa de alfabetismo y educación, o sea la adquisición de conocimiento

- Ingreso, es decir, los recursos para lograr un buen nivel de vida.

Según el PNUD (2002):

(...) las capacidades más elementales del desarrollo humano son tener una vida larga y en salud, recibir enseñanza, tener acceso a los recursos necesarios para alcanzar un nivel de vida aceptable, y poder participar de la vida de la comunidad a la que pertenece (p. 13).

Por otra parte, y en forma simultánea, se han ido elaborando planteamientos complementarios acerca del concepto de desarrollo humano, agregándole a las definiciones ligadas a los procesos sociales y de índole económica, aspectos humanos de carácter más individual; algunos de los cuales se deseacan a continuación.

Por ejemplo, León (1998) propone que al hablar de desarrollo humano, ha de pensarse en un concepto que considera todos los procesos y cambios que se dan desde la concepción hasta la muerte y que progresivamente van formando lo que es el ser humano en cada una de sus etapas.

En 1990, en el plano más personal, el PNUD, propone que "el desarrollo humano es un proceso mediante el cual se amplían las oportunidades de los individuos, las más importantes de las cuales son la vida prolongada y saludable, acceso a la educación y disfrute de un nivel de vida decente (p. 33).

Por otra parte, Papalia y Wendkos (1994), indican que cuando se hace refcrencia al estudio del desarrollo del niño, se debe entender éste como el estudio científico de las formas normales (tanto cualitativas como cuantitativas) en que los niños cambian con el paso del tiempo. 
En ese mismo sentido, para TRIPOD (2001), el desarrollo humano es el estudio científico de cómo cambian las personas y cómo permanecen algunos aspectos con el correr del tiempo.

En 1997, Craig plantea que el desarrollo humano es un proceso complejo y rico, lleno de interrogantes y retos; lo concibe como una mezcla entre lo biologico y lo cultural, en donde la participación del pensamiento y los sentimientos son relevantes. Es un proceso que inicia en la concepción y se da por toda la vida, en el cual cada individuo se desarrolla en forma única dentro de un contexto particular de relaciones, familia, comunidad, historia y circunstancias.

En esta misma línea, León (2001) propone que el desarrollo humano es el conjunto de cambios, procesos y mecanismos internos y externos, que interactúan en los seres humanos en los planos físico, cognitivo, lingüistico y socioemocional, desde la concepción hasta la mucrte y que repcrcuten en forma integral y única en los diferentes aspectos y contextos de sus vidas.

Como puede notarse en las anteriorcs definiciones, que no dejan por fuera los contextos sociales, culturales, históricos y económicos, la concepción de desarrollo humano con mayores aplicaciones desde la perspectiva educativa es la que se centra más en el individuo como ser único, con sus características, necesidades, problemas y potencialidades.

No es coincidencia que la definición esencial del concepto educación establece que esta es la acción de desarrollar las facultades físicas, intelectuales y morales (García, Pelayo y Gross, 1976).

En este sentido el desarrollo interactúa bidireccionalmente en forma constante con el aprendizaje, que se analiza más adelante y que es el principal mecanismo de la educación, para impulsar formas nuevas de actuar, pensar y sentir. Por su parte, sin aprendizaje difícilmente habría desarrollo, por lo que ambos representan elementos claves en el desenvolvimiento humano.

\section{El desarrollo humano de cara al nuevo siglo}

Para analizar el tema del desarrollo humano es necesario, en primera instancia, retomar el marco histórico en que se ha desenvuelto la especie humana, y la repercusión que los distintos eventos claves ha tenido en su desarrollo.

No es el objetivo de este artículo hacer un recorrido histórico de la humanidad, pero sí resaltar algunos aspectos tales como:

a) El ser humano ha evolucionado en su dominio intelectual y en sus capacidades físicas (como crecimiento y longevidad) pero se ha mantenido fundamentalmente en un nivel primitivo de desarrollo emocional (Goleman, 1995). 
En este sentido, es posible decir que el ser humano ha desarrollado enornes potenciales y conocimientos que han permitido logros como la conquista del espacio, el desarrollo tecnológico y la guerra contra las enfermedades, entre otros. A nivel físico tambien ha mejorado su nutrición y crecimiento, cada vez se vive más y con mayor calidad de vida. No obstanteestos alcances, la vida emocional de las personas continúa desenvolviendose fundamentalmente con los mismos mecanismos de reacción de hace muchos siglos, por lo que la falta de control de los sentimientos y conductas ha conducido a muchos problemas en las relaciones interpersonales y ha repercutido incluso en ámbitos internacionales.

b) Los cambios dados en las últimas decadas en el desarrollo de la humanidad, como por ejemplo: la pérdida del control social, el desarrollo de la drogadicción y otras formas de escapes, las búsquedas de diversa índole para darle sentido a la vida, la generación de movimientos religiosos, políticos, militares y de otra índole, la globalización de la información, la destrucción de los recursos naturales; han conllevado a cambios significativos en las condiciones del desarrollo humano a nivel individual y colectivo. Algunos de estos cambios han favorecido el desartollo, pero muchos de ellos confirman que a pesar de los avances, el ser humano aún enfrenta limitaciones importantes para lograr alcanzar su máximo potencial.

c) De esta forma los cambios generados han marcado una enorme diferencia en la disponibilidad de conocimientos; ha conllevado a una sobrecarga de información, pero por otro lado, tambien a una necesidad de generar nuevos procesos educativos que le permitan a las personas enfrentar los retos del siglo XXI con un verdadero sentido de capacidad y con la versatilidad necesaria para adaptarse a nuevas formas de trabajo y de vida, sin sacrificar sus valores y su esencia como seres humanos. Esta "nueva educación" debe aportarle a las personas instrumentos y herramientas para hacerle frente a estas nuevas condiciones de vida, a la sobrecarga de conocimientos, a la variedad de tipos de información que están disponibles, y a la vez, permitir alguna forma coherente de construcción de conocimientos y de una cultura que a la vez que sea globalizada, también mantenga los rasgos locales y de identificación que le dan sentido a una sociedad o comunidad.

\section{La integralidad del desarrollo}

Otro elemento clave para comprender cómo abordar la temática del desarrollo tiene que ver con su integralidad, que a nivel teórico pareciera fácil de comprender, peroque en la práctica, especialmente cducativa, es difícil de implementar. 
En primer lugar, el desarrollo humano se presenta en un contexto históricosocial dado, por lo que actualmente, la persona se ve influida por la globalización y la tecnología, la cultura, la sociedad en que se mueve, la comunidad donde vive, la familia, el sistema educativo y otros elementos de su entomo.

Por otra parte, el desarrollo, para ser estudiado, puede subdividirse en múltiples áreas, siendo las más reconocidas la física, la cognitiva, la linguística y la socioemocional, dentro de esta última generalmente se consideran también los aspectos sexuales y morales.

Un primer elemento a tomar en cuenta se refiere a que esta visión "artificial" no opera así en la realidad, pues la persona se desenvuelve como un todo. Por tanto, aún desde el punto de vista teórico, se requiere no solamente tomar cada área, sino realizar los cruces entre áreas que garantizarían una visión realmente "integral" del desarrollo.

Cómo puede observarse en el siguiente gráfico, el desarrollo en realidad es el punto central donde convergen todas las áreas del desarrollo; no obstante, es por su dificultad de estudio simultáneo, que se subdivide en las áreas propuestas:

\section{Gráfico 1}

\section{El desarrollo como proceso integral}

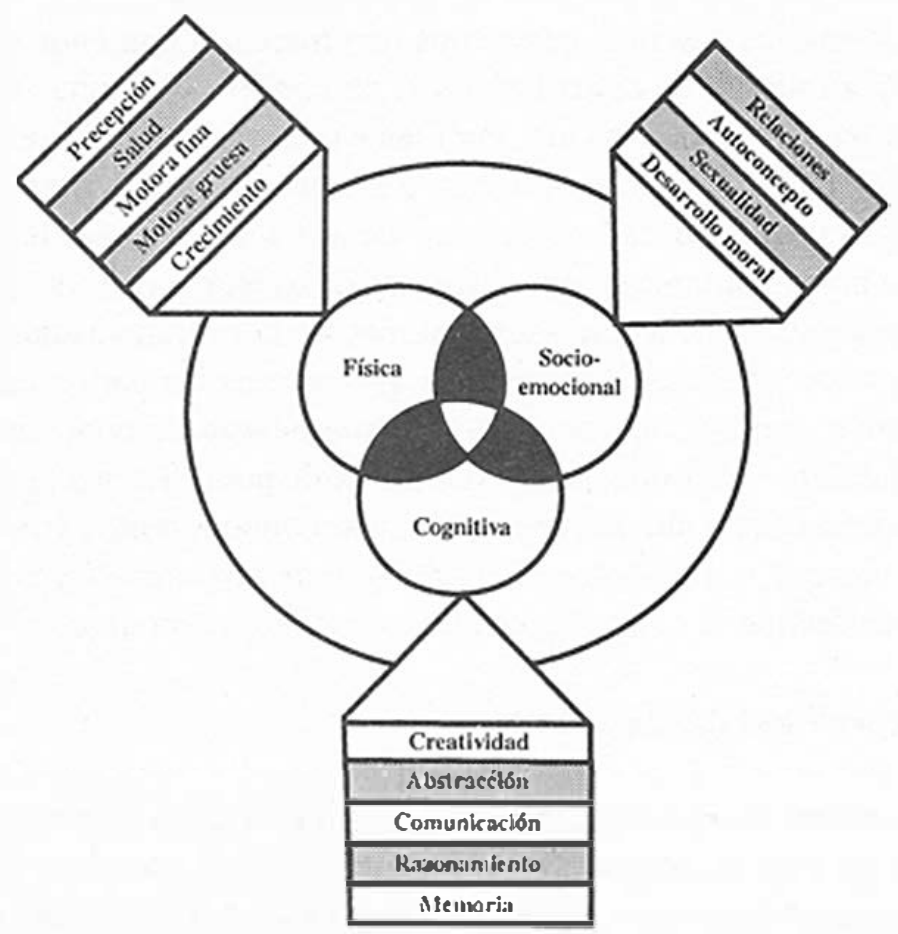

Fuentc: León, 1998. (p. 30). 
Asimismo, desde la perspectiva educativa, la integralidad del desarrollo debcría teóricamente de reflejarse en un "currículo integrado". No obstante, un currículo de esta naturaleza es más fácil de elaborar en el papel que de llevarse efectivamente a la práctica.

Por ejemplo, una lección o actividad podría tener una naturaleza fundamentalmente cognitiva, pero a su vez podría fortalecer el componente lingüístico, y dependiendo de su naturaleza, el componente social y emocional.

Por tanto, una actividad de educación física a su vez, puede contener elementos cognitivos si el docente los propone, y casi siempre involucra la autoestima y las relaciones de la persona. La mayoria de los aprendizajes en el aula preescolar y escolar puede mezclar componentes de la distintas áreas, lo cuál además de atender las distintas necesidades, contribuiria a un abordaje más integral del aprendizaje y el desarrollo.

Podría decirse que, sea que el docente esté consciente o no, y lo haya plancado así o no, en casi todo momento, en la práctica, las actividades tienden a involucrar más de una área. Por ejemplo, durante una práctica de matemáticas, generalmente los niños y niñas interactúan entre sí, se critican o refuerzan, se mueven por el aula, etc. Si el educador asumiera con mayor conciencia estos aspectos, tendría más oportunidad de aprovechar cada actividad y talvez podría convertir cada lección en algo más interesante y motivante para sus alumnos.

\section{El desarrollo como producto de la interacción permanente de factores internos y externos}

Otro rasgo importante de tomar en cuenta en materia del desarrollo humano individual es el hecho de que prácticamente todos los cambios que se dan en la persona desde la concepción hasta la muerte, son el resultado de la interacción de factores internos y externos que operan en forma simultánca, aunque en algunos momentos unos prevalczcan sobre otros.

Es decir, los factores internos como: la genética, la biología, la maduración, el crecimiento, la fisiología y la autoestima, entre otros, establecen un conjunto de condiciones que interactúan con los elementos externos, que tienen que ver principalmente con el ambiente ecológico, la cultura, la sociedad, la familia, la comunidad y el centro educativo en que se desenvuelve la persona.

La incorporación de los elementos externos al sistema interno se da fundamentalmente a través de uno de los principales mecanismos del desarrollo, denominado aprendizaje. El aprendizaje puede ser considerado entonces como $\mathrm{cl}$ conjunto de cambios en matcria de conocimientos, actitudes y habilidades que son fundamentalmente permanentes y que van contribuyendo al desarrollo físico, cognitivo, lingüístico y socioemocional de cada persona a través de su vida. 
Desde la perspectiva del educador, esta interacción no es simple, pues implica que cuando se considera alguna situación especial que presenta un alumno(a), generalmente la explicación no está en un sólo factor, sino que más bien es el resultado de la interacción de varios factores internos y externos, que actúan entre sí como precipitantes de una problemática.

\section{El desarrollo es un proceso continuo con retos y expectativas diversas}

El desarrollohumano es un proceso complejo y multifactorial que muestra ciertas características comunes en las distintas etapas en que éste es dividido para su análisis. Bojorquez y Montero (s.f.) opinan que el desarrollo, humano es el estudio científico de cómo cambian las personas y cómo permanecen algunos aspectos con el correr del tiempo.

Aunque no existe un consenso total sobre las etapas, al igual que es el caso de las áreas, pues se puede considerar formularlo a nivel de etapas globales, o a nivel de etapas y subetapas, para efectos de este trabajo y por su vinculación directa con los procesos educativos, se propone visualizar el desarrollo fundamentalmente en las siguientes etapas:

\section{Gráfico 2 \\ Principales etapas del desarrollo humano}

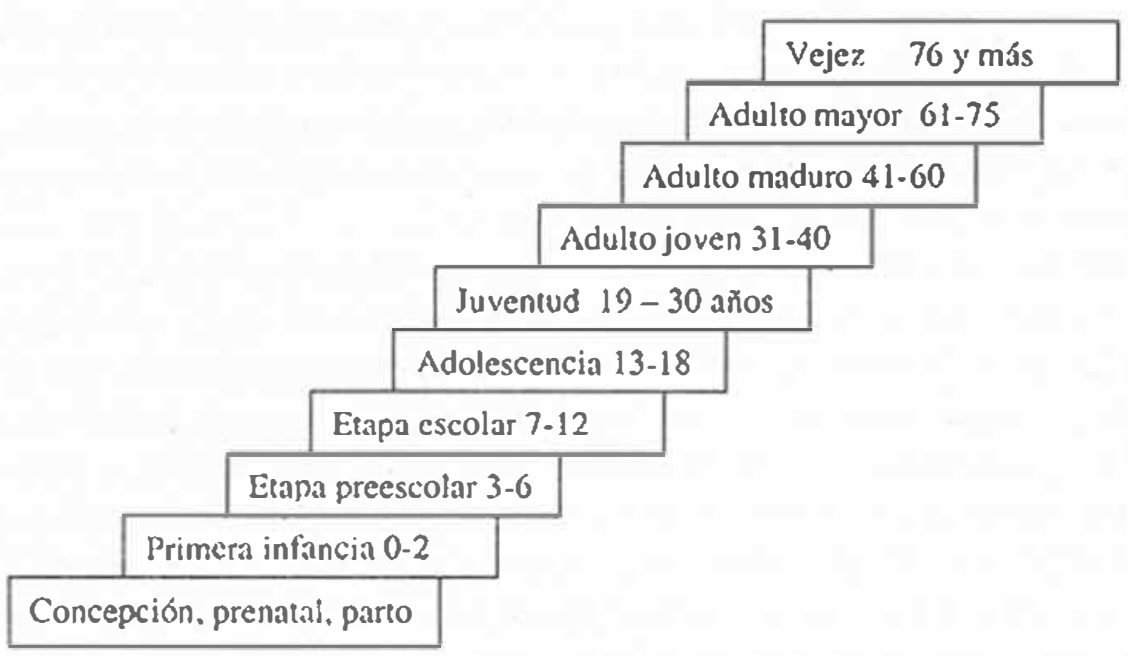


Como se mencionó anteriormente, algunas de las etapas pueden subdividirse a su vez en subetapas; por ejemplo, en el caso de la etapa escolar, se pueden considerar al menos dos subetapas, de 7-9 años y de 10-12 años. Se consideró que retomar las subetapas va más allá del objetivo del presente trabajo; no obstante, debe quedar claro que ćstas existen y que se observan algunas diferencias relevantes dentro de las mismas etapas.

Cada etapa, presenta ciertas características, necesidades, problemas y potencialidades típicas de desarrollo. Aunque no se puede decir que estas características son universales, pues se dan variaciones por cultura, la tendencia es que la mayoría de las personas especialmente en el mundo occidental, sí las presentan.

Se presenta a continuación una breve panorámica de algunas de las principales características de estas etapas. Si el lector desea conocerlas con mayor detalle, puede consultar las referencias bibliográficas aportadas al final del artículo. La matriz ha sido elaborada por las autoras a partir de la literatura existente.

\section{MATRIZ DE ELEMENTOS CRUCIALES PARA CADA ÁREA Y ETAPA}

\begin{tabular}{|c|c|c|c|c|}
\hline ETAP'VÁREA & FISICA & C.OGNITIVA & I.INGUISTIC, & SOCDOARX) \\
\hline Prenatal & $\begin{array}{l}\text { Formación de } \\
\text { órganos y de la } \\
\text { estructura corporal } \\
\text { b́́sica. Crecimiento } \\
\text { físico acelerado. }\end{array}$ & Se forma cl cerebro. & $\begin{array}{l}\text { Se desarrolla el oido } \\
\text { y el aparato } \\
\text { fonoarticulador. }\end{array}$ & $\begin{array}{l}\text { Se observa } \\
\text { vulnerabilidad a } \\
\text { influcncias } \\
\text { ambientaks. }\end{array}$ \\
\hline 0.2 aitos & $\begin{array}{l}\text { Los sentidos } \\
\text { funcionan desde el } \\
\text { nacimiento. }\end{array}$ & $\begin{array}{l}\text { Se intensifica el } \\
\text { decarrolio del cerebro } \\
\text { según la estimulación } \\
\text { recibida. Se consolida } \\
\text { el desarollo } \\
\text { perceprual. }\end{array}$ & $\begin{array}{l}\text { El habla se desorrolla } \\
\text { con rapidez, } \\
\text { dependiendo de la } \\
\text { maduración y la } \\
\text { estimulación del } \\
\text { cntomo. }\end{array}$ & $\begin{array}{l}\text { Se formin lazos } \\
\text { afectivos cruciales } \\
\text { con los padres. Se } \\
\text { inicia el interes en } \\
\text { deros niños. }\end{array}$ \\
\hline $3 \cdot 6$ años & $\begin{array}{l}\text { Desamallo de las } \\
\text { habilidades mororas, } \\
\text { principalmentc } \\
\text { gruesas. }\end{array}$ & $\begin{array}{l}\text { El pensamicnto es } \\
\text { aún poco lógico y es } \\
\text { egocentrico. Se } \\
\text { inicia cl desarrollo } \\
\text { de la creatividad, la } \\
\text { inventiva col los } \\
\text { juegos y la } \\
\text { imaginación. }\end{array}$ & $\begin{array}{l}\text { Mayor desarrollo de } \\
\text { Ia habilidad } \\
\text { linglística. Aumenta } \\
\text { el vocabulario. } \\
\text { mejora ba } \\
\text { pronunciacion. }\end{array}$ & $\begin{array}{l}\text { Intensifica la } \\
\text { relación con otros } \\
\text { niños. Incrementa el } \\
\text { autocontrol. el } \\
\text { cuidado propio y el } \\
\text { sentido de } \\
\text { independencia. }\end{array}$ \\
\hline $7-12$ años & $\begin{array}{l}\text { Mejora la fuerza y las } \\
\text { habilidades motrices } \\
\text { lina y gniesa. }\end{array}$ & $\begin{array}{l}\text { Se da el pensamiento } \\
\text { concreto. Disminuye } \\
\text { el egocentrismo. Se } \\
\text { incrementa la } \\
\text { memoria. }\end{array}$ & $\begin{array}{l}\text { Incremento del } \\
\text { lenguaje. Desarrolla } \\
\text { el lenguaje escrito. }\end{array}$ & $\begin{array}{l}\text { Desarrollo del } \\
\text { autoconcepto y la } \\
\text { autocstima. }\end{array}$ \\
\hline
\end{tabular}




\begin{tabular}{|c|c|c|c|c|}
\hline 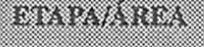 & (1910: & 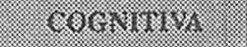 & 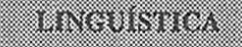 & 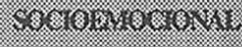 \\
\hline $13-18$ años & $\begin{array}{l}\text { Disminuye la } \\
\text { rapidez del } \\
\text { crecimiento físico. } \\
\text { Mejora la fuerza y } \\
\text { capacidad atlética. } \\
\text { Cambios físicos } \\
\text { rápidos y } \\
\text { profundos. Se inicia } \\
\text { la madurez sexual }\end{array}$ & $\begin{array}{l}\text { Desarrollo del } \\
\text { pensamiento } \\
\text { abstracto y empleo } \\
\text { del razonamiento } \\
\text { científico, si se da la } \\
\text { oportunidad. } \\
\text { Egocentrismo en } \\
\text { algunos } \\
\text { comportamientos. }\end{array}$ & $\begin{array}{l}\text { Desarrolla la } \\
\text { capacidad para la } \\
\text { lectura y análisis de } \\
\text { textos más } \\
\text { abstractos. } \\
\text { Usualmente ha } \\
\text { logrado el dominio } \\
\text { del lenguaje verbal. }\end{array}$ & $\begin{array}{l}\text { Difícil búsqueda y } \\
\text { consolidación de la } \\
\text { identidad. Los pares } \\
\text { ayudan a desarrollar y } \\
\text { probar el autocontrol. } \\
\text { Suelen tener buenas } \\
\text { relaciones con los } \\
\text { padres. }\end{array}$ \\
\hline $19-30$ años & $\begin{array}{l}\text { La salud física llega } \\
\text { a su máxima } \\
\text { expresión. }\end{array}$ & $\begin{array}{l}\text { Se observa una } \\
\text { capacidad } \\
\text { intelectual más } \\
\text { compleja. Se da la } \\
\text { elección de carrera. }\end{array}$ & $\begin{array}{l}\text { Según el tipo de } \\
\text { trabajo y carrera se } \\
\text { incrementa el } \\
\text { vocabulario y el } \\
\text { dominio del } \\
\text { lenguaje técnico. }\end{array}$ & $\begin{array}{l}\text { Continúa } \\
\text { desarrollándose el } \\
\text { sentido de la } \\
\text { identidad. Se toman } \\
\text { decisiones acerca de } \\
\text { las relaciones de } \\
\text { pareja. Muchos se } \\
\text { casan y tienen hijos. }\end{array}$ \\
\hline $30-40$ años & $\begin{array}{l}\text { La salud física decae } \\
\text { levemente. }\end{array}$ & $\begin{array}{l}\text { Se consolida el } \\
\text { desarrollo } \\
\text { productivo y la } \\
\text { capacidad } \\
\text { profesional o } \\
\text { técnica. }\end{array}$ & $\begin{array}{l}\text { Según el tipo de } \\
\text { trabajo, se continua } \\
\text { aprendiendo nuevos } \\
\text { conceptos }\end{array}$ & $\begin{array}{l}\text { Se da la formación } \\
\text { de la familia y el } \\
\text { crecimiento de los } \\
\text { hijos(as). }\end{array}$ \\
\hline $41-60$ años & $\begin{array}{l}\text { Se observan } \\
\text { primeros signos de } \\
\text { deterioro de la salud } \\
\text { física, el vigor y la } \\
\text { fuerza.Se da la } \\
\text { menopausia en las } \\
\text { mujeres. }\end{array}$ & $\begin{array}{l}\text { La sabiduría y la } \\
\text { habilidad para } \\
\text { resolver problemas } \\
\text { prácticos son } \\
\text { grandes.Algunos } \\
\text { experimentan el } \\
\text { éxito en sus carreras } \\
\text { y llegan a la cima } \\
\text { económica. }\end{array}$ & & $\begin{array}{l}\text { Nueva búsqueda del } \\
\text { sentido de la } \\
\text { vida.Hay mayor } \\
\text { responsabilidad al } \\
\text { cuidar hijos y padres } \\
\text { ancianos. } \\
\text { Independencia de } \\
\text { los hijos (nido } \\
\text { vacío). La mujer } \\
\text { muestra más } \\
\text { confianza en sí } \\
\text { misma; el varón más } \\
\text { expresividad. } \\
\text { Algunos/as sufren la } \\
\text { crisis de la edad } \\
\text { madura. }\end{array}$ \\
\hline 61-75 años y más & $\begin{array}{l}\text { La salud y las } \\
\text { habilidades físicas } \\
\text { decaen.Se observa } \\
\text { lentitud en las } \\
\text { reacciones, lo que } \\
\text { afecta aspectos del } \\
\text { funcionamiento. } \\
\text { Inminencia de la } \\
\text { muerte. }\end{array}$ & $\begin{array}{l}\text { La mayoría } \\
\text { mantiene una mente } \\
\text { despierta. }\end{array}$ & $\begin{array}{l}\text { Se pueden presentar } \\
\text { problemas de } \\
\text { comunicación }\end{array}$ & $\begin{array}{l}\text { Se da la necesidad de } \\
\text { afrontar pérdidas, } \\
\text { facultades, seres } \\
\text { queridostiempo } \\
\text { libre, pero en } \\
\text { muchos casos, con } \\
\text { menos dinero. } \\
\text { Búsqueda de sentido } \\
\text { a la vida. }\end{array}$ \\
\hline
\end{tabular}

Fuente: matriz elaborada por las autoras del artículo. 
El nuevo paradigma de los derechos de los niños, niñas y adolescentes apenas empieza a calar en el sistema educativo. Cabe resaltar que este enfoque es totalmente coherente con el enfoque del desarrollo humano que aqui se plantea, por lo que no es posible ignorar esta

nueva visión, que a mediano plazo puede llegar a darle un enorme empuje a la promoción del desarrollo humano en todas sus dimensiones y etapas.
Cada una de las etapas le presenta a la persona retos diferentes en cada una de las áreas de su desarrollo. Por ejemplo, enfrentar el mundo como preescolar exige completar el dominio de ciertos aspectos físicos, iniciarse en el mundo de la lectura y el aprendizaje formal, y lograr consolidar un nivel de independencia y seguridad que le permita hacer frente al mundo escolar.

En el caso del escolar, los retos que enfrenta son totalmente diferentes, pues generalmente su desarrollo físico ha alcanzado (o está alcanzando un dominio general) mientras que el aprendizaje de conceptos, así como el dominio de destrezas físicas y so-

ciales en el grupo de coetáneos se vuelve cada vez más importante y presenta mayores niveles de complejidad.

Esta información respecto a las diversas etapas y sus características debe ser ampliamente conocida por el personal docente que trabaja con niños(as). Esta necesidad incluye las etapas adultas, pues si se va a actuar con profesionalismo, se requiere reconocer los procesos propios que se están viviendo y no solamente las características básicas de los niños o niñas.

Por tanto se insta al lector a buscar información adicional a la presentada aquí para lograr reconocer en sí mismo y en los niños o niñas a su cargo, los principales procesos de desarrollo que se están viviendo. Solamente comprendiendo estos fenómenos se podrá brindar una atención integral a la niñez y auspiciar un aprendizaje para la vida.

\section{Los principios del desarrollo humano}

El desarrollo humano presenta un conjunto de principios que lo rigen, que son considerados importantes de recordar, especialmente a la luz de lo que algunos de ellos tienen que decir para la educación. 


\section{Principios del desarrollo más relevantes para la educación}

Es un proceso continuo de cambio.

Tiene dirección, es decir, sigue un patrón general, pero a su vez es flexible.

Es irreversible, por lo que aunguc se pucda modificar la percepción de un evento, éste seguirá formando parte de la persona.

Integra tanto factorcs intemos como externos, por lo que se ve afectado tanto por la vulnerabilidad interna de la persona como por las con. diciones del ambiente.

Marcha a un ritmo individual y va incorporando etapas sucesivas Avanza por maduración, imitación y experimentación.

Implica crecimiento y deterioro al mismo tiempo.

Las áreas del desarrollo son interdependientes y su desarrollo se da de lo gencral y simple a lo específico y complejo.

La estimulación sensorial es vital como mecanismo principal de cambio y de aprendizaje.

Está basado en necesidades humanas.

Se ve fuertemente influenciado por motivaciones inconscientes.

El éxito en cl logro de las habilidades gencra aún mayor éxito, por cl sentido de confianza y seguridad que genera.

Fuente: León (2003, Comunicación personal).

\section{La importancia de conocer los problemas del desarrollo, pero también sus potencialidades $y$ fortalezas}

El último de los principios mencionados en el punto anterior hace referencia a uno de los clementos más importantes de tomar en cuenta en la educación, especialmente si la educación cs vista como la promoción del desaitollo de las habilidades cognitivas y morales de la persona. Este principio cs clave porque implica que se deben conoccr, no solitmente las principales caractcrísticas, problemas y necesidades de los(as) cstudiantes, sino principalmente sus puntos fuertes y sus potencialidades.

Si cl docente aprovecha los puntos fucrtes de los alumnos(as) les fortalecerá su sentido de capacidad. Si cste sentido se fortalece, los niños(as) o adolescentes estarán en mejor condición de afrontar retos y dificultades, pues también sc verá fortalccida su autoestima. Si por el contrario, sc enfatizan sus problemas y limitaciones, se volverán más defensivos y resistentes al aprendizaje de cosas nucvas. 
Entre más conozca el docente a sus alumnos(as) en forma integral, mejor podrá identificar y fortalecer en cada uno de ellos(as) un talento, una habilidad o un interés; y sobre la base de éstos, estimular el aprendizaje de nucvos conceptos o incrementar la capacidad para enfrentar dificultades previas en el dominio de alguna noción o proceso.

Es interesante notar que cuando se le pide a los docentes mencionar los problemas que enfrentan los niños(as) en el centro educativo, es fácil elaborar csta lista. No obstante, cuando se les pide identificar también puntos fucrtes o habilidades, la lista tiende a ser más escueta. Mientras no se visualicen las fortalezas y sc aprovechen, difícilmente los alumnos(as) le harán frente a los rctos que la educación les plantea.

Asimismo, además de las características, necesidades, problemas, talentos y potencialidades, es neccsario finalizar este enfoque del desarrollo por lo que tal vez debía haberse iniciado, pero intencionalmentc no se ha hecho: los derechos de los niños, niñas y adolescentes a un desarrollo óptimo en todas las áreas; así como a una educación de calidad que efectivamente garantice el cumplimiento de todos sus derechos, y en este caso particular, los que tienen que ver con su educación en el sentido integral.

El nucvo paradigma de los derechos de los niños, niñas y adolescentes apenas empieza a calar en cl sistema cducativo. Cabc resaltar que este enfoque es totalmente coherente con el enfoque del desarrollo humano que aqui se plantea, por lo que no es posible ignorar csta nucva visión, que a mediano plazo pucde llegar a darlc un enorme empuje a la promoción del desarrollo humano en todas sus dimensiones y ctapas.

Como se ha visto en el presente artículo, existen concepciones difcrentcs, aunque complementarias, acerca del concepto de desarrollo humano. El que aquí se profundiza reitcra la integralidad del mismo, sus principales clementos por grupo ctárco y los principios que lo caracterizan.

Hasta aquí se analizó en detalle cl concepto de desarrollo humano, considcrándolo como el conjunto de cambios, procesos y mecanismos internos y extcrnos, que interactúan en los seres humanos en los planos físico, cognitivo, lingüístico y socioemocional, desde la concepción hasta la muerte y que repercuten en forma integral y única en los diferentes aspectos y contextos de sus vidas (León, citado por Lcón. Percira y Castro, 2003).

No obstante, ha de señalarse que además de los principios enunciados hasta cl momento, existen otros principios del desarrollo que están estrechamente vinculados al aprendizaje. Para darles la atención que cada uno de cllos requicrc, ćstos scrán tratados cn las páginas siguientes analizando cl concepto aprendizaje y su relación con cl desarrollo humano; además, se elabora un panorama 
que permite abordar las implicaciones pedagógicas, por áreas y etapas, que el desarrollo tiene y que deben ser conocidas por todo(a) educador(a) que desee incrementar su efectividad y realización como docente.

\section{El aprendizaje como proceso clave del desarrollo}

En concordancia con la cantidad y variedad de teorias de aprendizaje existentes (Papalia y Wendkos, 1994), es posible también encontrar una serie de conceptos de aprendizaje, así como formas de aprender y de enseñar. $\mathrm{Ha}$ de destacarse que aprender es algo inherente al ser humano, por ello puede decirse tambien que el aprendizaje va intrínsecamente ligado al desarrollo.

Cabe resaltar que existe gran variedad de teorias acerca del aprendizaje y en esa misma medida, estas han ido evolucionando y tomando en consideración aspectos que otras no habian considerado antes. Además de la definición de carácter humanístico, pueden destacarse las siguientes definiciones acerca del aprendizaje.

Desde el punto de vista conductual, el aprendizaje constituye un cambio de conducta que se produce por medio de estímulos y respuestas que se rclacionan de acuerdo con conductas mecánicas.

Desde el campo de la Gestalt, el aprendizaje es un proceso de obtención o modificación de insights, perspectivas o patrones de pensamiento.

Desde el campo cognoscitivo, el aprendizaje es un proceso de interacción mediante el cual la persona es capaz de obtener nuevas estructuras cognoscitivas o llegar a cambiar las antiguas. Dentro de este campo, se destacan distintas perspectivas.

En la perspectiva piagetiana, el aprendizaje es una actividad mental que supone un proceso constructivo y conlleva asimilación y acomodación. En el proceso de aprendizaje el sujeto no sólo construye conocimientos, sino que también, a partir de lo ya conocido y adquirido y con la nueva información, reorganiza los conocimientos y es entonces capaz de dar soluciones a las diversas situaciones a las que se enfrenta (Pereira, 1991). Piaget distingue dos tipos de aprendizaje:

- Aprendizaje en sentido amplio, que es sinónimo de desarrollo y tiene en su origen la equilibración, proceso central de la inteligencia. De este modo las exigencias de equilibrio entre asimilación y acomodación en el funcionamiento asimilador explican la construcción de las estructuras cognoscitivas.

- Aprendizaje en sentido estricto, que se origina por la difcrenciación de las estructuras mediante el proceso de acomodación. Equivale a la adquisición de conocimientos debido a una experiencia mediata. 
Por otra parte, Ausubel, Novak y Mayer (citados por Ausubel, Novak y Hanesean, 1989), desarrollan el concepto de aprendizaje significativo, uno de cuyos requisitos y condiciones necesarias es la significatividad del material. Desde su visión, los contenidos que se ofrecen al aprendizaje del niño tienen que poderse relacionar sustantivamente con los contenidos que forman la estructura cognoscitiva actual del aprendizaje. Solo de esa manera para ellos, el proceso de construcción, de asimilación y de acomodación pueden tener lugar. Statl (1980), menciona que cuando vemos la ejecución de cierto tipo de conducta y ésta ejecución se constituye en objeto de estudio, estamos entonces intentando comprender el proceso de aprendizaje.

Ausubel et al. (1989) asumen que en el aprendizaje existen aspectos que están relacionados con él y que deben ser tomados en cuenta; entre ellos mencionan el currículo, los materiales a utilizar, los estilos cognoscitivos de los estudiantes, entre otros.

El aprendizaje significativo comprende la adquisición de nuevos significados y a la inversa, éstos son producto del aprendizaje significativo. Ni el proceso, ni el resultado del aprendizaje serán posiblemente significativos si la tarea de aprendizaje no lo es potencialmente y si tampoco es relacionable, intencionada y sustancialmente, con su estructura cognoscitiva (p. 48).

Para Ausubel, et al. 1989, el tipo básico de aprendizaje significativo, del cual dependen todos los demás aprendizajes de esta clase, es el aprendizaje de representaciones, que consiste en hacerse del significado de símbolos solos (generalmente palabras) o de lo que éstos representan.

Como se nota, hay una gran diversidad de conceptualizaciones referidas al aprendizaje y cada una de ellas conlleva implicaciones de carácter pedagógico que es indispensable tomar en consideración. De ahí la importancia de que el docente tenga clara su visión de enseñanza y de aprendizaje pues de ahí se derivarán todas sus actuaciones y maneras de concebir la construcción del conocimiento o la adquisición del mismo. Asimismo, es posible señalar algunos principios propios del aprendizaje, que permitirán tener una mayor comprensión de las múltiples implicaciones pedagógicas que estos tienen. 


\section{PRINCIPIOS DEL APRENDIZAJE}

El aprender es espontánco y natural.

En los primeros años de vida se conforman las bases sobre las que se estructura la vida futura.

Existe en cl niño un sentido de logro importante, interés y motivación hacia el proceso de aprendizaje.

El aprendizaje de los conceptos requiere tiempo y variedad de experiencias y de niveles de complejidad.

El ritmo de aprendizaje ha de ser apropiado para que sea efectivo.

El aprendizaje debe partir de las cxperiencias de los estudiantes para que sea efectivoy duradero.

Se deben permitir los aprendizajes espontáncos que recurren al ensayo y error y respetar la motivacion del esiudiante.

El aprendizajc cs resultado de la interacción de factores internos y externos en constantc interacción.

Son condiciones para cl aprendizaje: la madurez delestudiante (física y neurológica), las situaciones de aprendizaje apropiadas en nivel, cantidad y calidad, que los contenidos y su nivel de dificultad estén en concordancia con el desarrollo cognitivo y lingüístico del estudiante.

Los aprendizajes son de carácter cognitivo, físico y socioemocional.

Existen diferentes formas dc aprender.

El juego es el principal medio de aprendizaje.

El centro educativo debc tener presente:

- Conocer y respetar cl rirmo y nivel de aprendizaje.

- Considerar intereses y necesidades.

- Ofrecer diversidad de expericncias de aprendizaje.

- Estimular los esfucrzos del esiudiante por aprender.

- La calidad de la enscñanza depende del número de alumnos por aula y de cuánto se aplican los conocimicntos sobre el desarrollo del niño.

- El docente debe conocer, comprender y aplicar los conocimientos básicos del desarrollo.

- El docente debe tener claros los fines y objetivos de la educacion.

(l.eón. Gurfinkiel y Jengich. 1988). 
Este conjunto de principios requiere ser analizado uno por uno para concretar su aplicación en el aula y las otras implicaciones que puede tener en la relación centro educativo-familia, así como en otros aspectos del proceso educativo, como puede ser las adecuaciones curriculares, las metodologías empleadas y toda la noción de evaluación que se aplica.

\section{Implicaciones educativas de la información vinculada al desarrollo}

El desarrollo constituye una de las bases fundamentales sobre las cuales se da el aprendizaje y el proceso educativo. En cada una de las etapas y áreas del desarrollo se pueden ubicar un conjunto de aplicaciones educativas de la información disponible. A efectos de ejemplificar la importancia de dichas implicaciones, se presenta a continuación, una matriz que muestra algunas de las implicaciones que a criterio de las autoras tiene el proceso de desarrollo en las prácticas educativas, sea en el seno del hogar o en cl centro educativo. Se plantcan las cuatroárcas básicas del desarrollo humano, a saber: física, cognitiva, socio-emocional y lingüística, según las diferentcs ctapas.

\section{Implicaciones del desarrollo en la educación}

\begin{tabular}{|c|c|c|c|c|}
\hline ElupadÁra & Ffsica & \multicolumn{2}{|c|}{ Cuknativo-L.ingỉ stica } & Suciuctuocional \\
\hline Etapa prenatal & $\begin{array}{l}\text { Informar a las } \\
\text { madres sobre la } \\
\text { importancia de los } \\
\text { cuidados de la } \\
\text { madre. }\end{array}$ & $\begin{array}{l}\text { Atender la } \\
\text { alimentacion de la } \\
\text { madre, para que } \\
\text { cvitc la desnutrición } \\
\text { prenatal. }\end{array}$ & $\begin{array}{l}\text { Promover el } \\
\text { vínculo con el bebé } \\
\text { mediante música. } \\
\text { conversaciones. }\end{array}$ & $\begin{array}{l}\text { Promover la } \\
\text { aceplación del bele } \\
\text { por lodos los que } \\
\text { rodean a la madre. }\end{array}$ \\
\hline 0.2 aijos & $\begin{array}{l}\text { Garantixar las } \\
\text { condicioncs de } \\
\text { seguridad, } \\
\text { nutrición. ejercicio } \\
\text { y salud requeridas } \\
\text { para cl desarrollo } \\
\text { sano del bebé. } \\
\text { Orrecer muchas }\end{array}$ & $\begin{array}{l}\text { Iniciar la } \\
\text { estimulación } \\
\text { intelectual y } \\
\text { linguística del } \\
\text { bubé. } \\
\text { fundamentalmentc } \\
\text { a través del juego. }\end{array}$ & $\begin{array}{l}\text { Fstimular cl } \\
\text { lenguaje mediante } \\
\text { el juego con } \\
\text { sonidos. sílabas y } \\
\text { la repetición de } \\
\text { palabras } \\
\text { pronunciadas } \\
\text { correctamentc. }\end{array}$ & $\begin{array}{l}\text { Promover el } \\
\text { eslablecimiento de } \\
\text { un vínculo fucric y } \\
\text { seguro con al } \\
\text { menos un adulto. } \\
\text { Estimular en todos } \\
\text { los sentidos al niño } \\
\text { y ofrecerle } \\
\text { oporlunidades pora }\end{array}$ \\
\hline
\end{tabular}




\begin{tabular}{|c|c|c|c|c|}
\hline 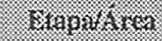 & 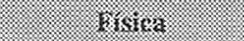 & \multicolumn{2}{|c|}{ 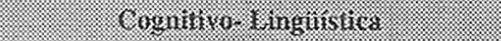 } & 850 croentociontal \\
\hline & $\begin{array}{l}\text { actividades } \\
\text { especialmente para } \\
\text { el desarrollo motor } \\
\text { grueso y fino. } \\
\text { Promover, hacia los } \\
\text { dos años, acciones } \\
\text { para el control de } \\
\text { esfínteres. }\end{array}$ & $\begin{array}{l}\text { Ofrecerle } \\
\text { actividades de } \\
\text { estimulación } \\
\text { acordes a su edad, } \\
\text { así como materiales } \\
\text { y juguetes seguros } \\
\text { que lo involucren } \\
\text { según su nivel de } \\
\text { desarrollo físico e } \\
\text { intelectual. } \\
\text { Permitir al niño } \\
\text { relacionarse } \\
\text { activamente con el } \\
\text { medio. } \\
\text { Plantearle } \\
\text { diferentes } \\
\text { situaciones de } \\
\text { juego en la que se } \\
\text { presenten } \\
\text { conflictos que deba } \\
\text { resolver según sus } \\
\text { capacidades } \\
\text { cognitivas. } \\
\text { Estimular el } \\
\text { lenguaje mediante } \\
\text { el juego con } \\
\text { sonidos, sílabas y } \\
\text { la repetición de } \\
\text { palabras } \\
\text { pronunciadas } \\
\text { correctamente. } \\
\text { Estimular los } \\
\text { intentos de } \\
\text { comunicación de } \\
\text { los niños.Promover } \\
\text { que el niño utilice } \\
\text { su propio nombre. }\end{array}$ & $\begin{array}{l}\text { Estimular los } \\
\text { intentos de } \\
\text { comunicación de } \\
\text { los niños. } \\
\text { Promover que el } \\
\text { niño utilice su } \\
\text { propio nombre. }\end{array}$ & $\begin{array}{l}\text { la exploración del } \\
\text { entorno. Brindar } \\
\text { expresiones de } \\
\text { afecto al niño y } \\
\text { recibir las de éste, } \\
\text { de manera que se } \\
\text { establezca una } \\
\text { apropiada } \\
\text { comunicación con } \\
\text { los padres. }\end{array}$ \\
\hline 3.6 años & $\begin{array}{l}\text { Aprovechar cada } \\
\text { oportunidad para } \\
\text { consolidar el } \\
\text { desarrollo motor } \\
\text { grueso y estimular } \\
\text { la motora fina a } \\
\text { diferentes niveles } \\
\text { de complejidad. }\end{array}$ & $\begin{array}{l}\text { Promover } \\
\text { actividades y } \\
\text { juegos educativos } \\
\text { de toda naturaleza. } \\
\text { Brindarle al niño } \\
\text { apoyo para } \\
\text { desarrollar su } \\
\text { curiosidad e interés } \\
\text { por el mundo. } \\
\text { Promover } \\
\text { actividades como; } \\
\text { construir } \\
\text { rompecabezas de } \\
\text { mayor nivel de }\end{array}$ & $\begin{array}{l}\text { Pronunciar muy } \\
\text { despacio, claro y } \\
\text { correctamente } \\
\text { todas las palabras. } \\
\text { Promover a través } \\
\text { de preguntas, que } \\
\text { los niños elaboren } \\
\text { frases cada vez más } \\
\text { largas y complejas, } \\
\text { utilicen plurales y } \\
\text { tiempos verbales. } \\
\text { Fortalecer el } \\
\text { intercambio } \\
\text { lingüístico y }\end{array}$ & $\begin{array}{l}\text { Promover el inicio } \\
\text { de las conductas } \\
\text { autónomas y de } \\
\text { manifestación de } \\
\text { indepedencia en } \\
\text { procesos de } \\
\text { alimentación, } \\
\text { higiene y vestido. } \\
\text { Promover el } \\
\text { intercambio de los } \\
\text { niños con sus } \\
\text { iguales, } \\
\text { fortaleciendo las } \\
\text { relaciones }\end{array}$ \\
\hline
\end{tabular}




\begin{tabular}{|c|c|c|c|c|}
\hline (2). & Irision: & \multicolumn{2}{|c|}{ 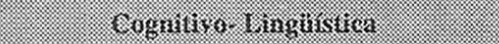 } & 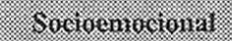 \\
\hline & & $\begin{array}{l}\text { complejidad, } \\
\text { discriminar, formar } \\
\text { figuras geométricas } \\
\text { y construir torres, } \\
\text { emparejar o } \\
\text { seleccionar } \\
\text { colores:señalar y } \\
\text { nombrar las partes } \\
\text { del cuerpo describir } \\
\text { acciones a partir de } \\
\text { ilustraciones. }\end{array}$ & $\begin{array}{l}\text { promover el } \\
\text { aumento de } \\
\text { vocabulario, } \\
\text { mediante } \\
\text { estrategias como la } \\
\text { lectura. }\end{array}$ & $\begin{array}{l}\text { interpersonales. } \\
\text { Estimular la } \\
\text { contestación de } \\
\text { preguntas sociales } \\
\text { (nombre, edad). }\end{array}$ \\
\hline 7-12 años & $\begin{array}{l}\text { Ofrecer } \\
\text { oportunidades para } \\
\text { el movimiento y el } \\
\text { ejercicio durante el } \\
\text { período escolar. } \\
\text { Brindar la } \\
\text { posibilidad de que } \\
\text { los estudiantes } \\
\text { ejerciten su cuerpo } \\
\text { y fortalezcan sus } \\
\text { capacidades físicas } \\
\text { en juegos y } \\
\text { deportes. }\end{array}$ & $\begin{array}{l}\text { Tomar en cuenta el } \\
\text { nivel de desarrollo } \\
\text { cognitivo que } \\
\text { presentan los } \\
\text { alumnos(as). } \\
\text { Ofrecer material } \\
\text { concreto para que } \\
\text { los estudiantes } \\
\text { refuercen sus } \\
\text { argumentos y } \\
\text { comprueben sus } \\
\text { razonamientos. } \\
\text { Promover el } \\
\text { intercambio } \\
\text { cognitivo entre los } \\
\text { estudiantes y dar } \\
\text { posibilidades para } \\
\text { la resolución de } \\
\text { conflictos } \\
\text { cognoscitivos. }\end{array}$ & $\begin{array}{l}\text { Promover la } \\
\text { lectoescritura y las } \\
\text { oportunidades de } \\
\text { expresarse } \\
\text { oralmente, según el } \\
\text { nivel de desarrollo. } \\
\text { Motivar a los } \\
\text { estudiantes al } \\
\text { aprendizaje de } \\
\text { diferentes } \\
\text { lenguajes: } \\
\text { computacional, } \\
\text { artístico, etc. }\end{array}$ & $\begin{array}{l}\text { Vigilar y apoyar las } \\
\text { conductas } \\
\text { prosociales y de } \\
\text { empatía entre los } \\
\text { niños. Brindar al } \\
\text { niño la oportunidad } \\
\text { de expresarse } \\
\text { libremente, de } \\
\text { contar con el } \\
\text { estímulo y el } \\
\text { refuerzo necesario } \\
\text { para formar su } \\
\text { autoconcepto. } \\
\text { Mantener en mente } \\
\text { la importancia que } \\
\text { la familia sigue } \\
\text { teniendo para el } \\
\text { niño(a). Modelar y } \\
\text { enseñar valores y } \\
\text { conductas } \\
\text { prosociales. } \\
\text { Analizar con } \\
\text { ellos(as) el impacto } \\
\text { de la tecnología. }\end{array}$ \\
\hline $13-18$ años & $\begin{array}{l}\text { Dar a los jóvenes la } \\
\text { oportunidad de } \\
\text { contar con la } \\
\text { alimentación y el } \\
\text { ejercicio necesario } \\
\text { para su adecuado } \\
\text { crecimiento. } \\
\text { Promover los } \\
\text { deportes. }\end{array}$ & $\begin{array}{l}\text { Formular } \\
\text { contenidos y } \\
\text { metodologías que } \\
\text { partan de los } \\
\text { intereses de los } \\
\text { estudiantes. Dar } \\
\text { oportunidad al } \\
\text { estudiante para la } \\
\text { formulación de } \\
\text { hipótesis ante } \\
\text { situaciones } \\
\text { conflictivas que se } \\
\text { les presenten. }\end{array}$ & $\begin{array}{l}\text { Promover la lectura } \\
\text { y el análisis crítico } \\
\text { de los mensajes en } \\
\text { medios, juegos de } \\
\text { video y otros. }\end{array}$ & $\begin{array}{l}\text { Reconocer la } \\
\text { importancia e } \\
\text { influencia de las } \\
\text { amistades. Brindar } \\
\text { oportunidades para } \\
\text { el intercambio } \\
\text { interpersonal } \\
\text { dentro de un clima } \\
\text { de respeto y } \\
\text { solidaridad. } \\
\text { Analizar con } \\
\text { ellos(as) lo } \\
\text { relacionado con el } \\
\text { respeto de limites. }\end{array}$ \\
\hline $19-40$ años & $\begin{array}{l}\text { Mantener una } \\
\text { alimentación, } \\
\text { ejercicio y cuidado } \\
\text { apropiado de la }\end{array}$ & $\begin{array}{l}\text { Mantener la } \\
\text { motivación inicial } \\
\text { de aprender a } \\
\text { aprender. Continuar }\end{array}$ & $\begin{array}{l}\text { Continuar } \\
\text { desarrollando el } \\
\text { lenguaje. }\end{array}$ & $\begin{array}{l}\text { Procurar el } \\
\text { equilibrio en la } \\
\text { salud mental y } \\
\text { emocional. }\end{array}$ \\
\hline
\end{tabular}




\begin{tabular}{|c|c|c|c|c|}
\hline Fגapalf rea & Fisica & \multicolumn{2}{|c|}{ Coguitivo- J.Inglitstica } & Sociecuteciental \\
\hline & $\begin{array}{l}\text { salud. Dormir y } \\
\text { descansar lo } \\
\text { suficiente. }\end{array}$ & $\begin{array}{l}\text { Ia colucación más } \\
\text { alla de la } \\
\text { graduación. }\end{array}$ & & $\begin{array}{l}\text { Consolidar el estilo } \\
\text { de vida que se desce } \\
\text { llevar. }\end{array}$ \\
\hline 41.60 aก̃os & $\begin{array}{l}\text { Procurar milniener } \\
\text { un ritmo de vidla } \\
\text { adecuado. } \\
\text { Conocer los } \\
\text { propios proiesos } \\
\text { para identificar } \\
\text { cambios. } \\
\text { Reconocer los } \\
\text { cambios y su } \\
\text { impacto en el } \\
\text { Isabojo. }\end{array}$ & $\begin{array}{l}\text { Manienerse } \\
\text { aprendiendo a } \\
\text { aprender. Procurar } \\
\text { producir más alls } \\
\text { de lo requerido. }\end{array}$ & $\begin{array}{l}\text { Continuar } \\
\text { promoviendo el } \\
\text { dcsarrollo } \\
\text { linguístico a través } \\
\text { de la Icclura y } \\
\text { olros medios. }\end{array}$ & $\begin{array}{l}\text { Manicres relaciones } \\
\text { positivas y } \\
\text { duraderas con } \\
\text { familiares y } \\
\text { atnistades. Si se } \\
\text { irabaja como } \\
\text { imaestrola). } \\
\text { mantener fuentes de } \\
\text { afecto fuera dei aula. }\end{array}$ \\
\hline $60 .+75$ años & $\begin{array}{l}\text { Vigilar la salud.el } \\
\text { ejercicio y el } \\
\text { descanso. } \\
\text { Mantenerse activo. }\end{array}$ & $\begin{array}{l}\text { Continuar } \\
\text { produciendo. }\end{array}$ & $\begin{array}{l}\text { Mantcicrse } \\
\text { informado. }\end{array}$ & $\begin{array}{l}\text { Mantener relaciones } \\
\text { con familiares y } \\
\text { amistades. }\end{array}$ \\
\hline
\end{tabular}

Fuenie: matriz claborada pos las autoras del articulo.

Sc estima que este panorama puede ser útil para iniciar un proceso de reflexión sobre la importancia del desarrollo humano en los procesos de aprendizaje y por tanto, en la educación. Sobre el desarrollo humano se conoce cada día más, por lo que se insta al lector a mantenerse actualizado, especialmente en lo que concierne a la clapa propia que eslá viviendo como a la de los alumnos(as) que atiende.

El desarrollo humano interactúa estrechamentc con el aprendizaje y la educación; de hecho, el primero constituye la base o punto de partida de los otros dos. A la vez, y en un proceso bidireccional, el aprendizaje y la educación repercuten e impulsan el desarrollo humano en todas las etapas de la vida. Por ende, entre el(la) docente mejor conozca estas interacciones, estará en mejor condición para promover ambos el desarrollo y el aprendizaje. 


\section{Referencias}

Ausubel, D; Novak, J. y Hanesean, H. (1989). Psicologia educativa: un punto de vista cognoscitivo. México: Editorial Trillas.

Bojorquez, R. y Montero, D. (s.f.). Etapas del desarrollo humano. En línea: http://www.contadores.cedc.uchile.cl.

Craig, G. (1997). Desarrollo psicológico. México: Prentice Hall.

División de Educación Básica. (2001) Trabajo sobre áreas disciplinarias del conocimiento que dan findamento a las carreras de la División de Educación Básica . Heredia: CIDE, Universidad Nacional.

Garcia Pelayo y Gross, R. (1976). Pequeino Larousse Ilustrado. París: Ediciones Larousse.

Goleman, D. (1995). Emotional lntelligence. New York: Bantam Books.

León, A., Gurfinkiel, S. y Jengich, A. (1988). El aprendizaje en el niño preescolar: Colección. Universidad Nacional: Instituto del Niño.

León, A. (1998). El maestro y los niños: la humanización del aula. San José, Costa Rica: Editorial Universidad de Costa Rica.

León, A. (2001), ¿Por qué se odia el aprendizaje? Educación y Familia, (1) n 1, p. 14

León, A. (2003). Principios del desarrollo. Comunicación personal.

León, A., Pereira, Z., y Castro, M. (2003). Análisis de los procesos cognitivos y pedagógicos que se aplican en el aprendizaje de cinco conceptos básicos del Programa de Educación Preescolar del Ministerio de Educación Pública y el desarrollo de estos conceptos en $2^{\circ}$ y $4^{\circ}$ nivel de la Educación General Básica. Informe Final de Investigación. Heredia, Costa Rica: DEB-CDE, Universidad Nacional.

Papalia, D. y Wendkos, S. (1994). Psicologia del desarrollo: de la infancia a la adolescencia. México: McGraw Hill. 
Pereira, 2. (1991). Aprendizaje operatorio para niños de tercer año con bajo rendimiento en matemáticas. Tesis de Maestría en Psicología. San José, Costa Rica: Sistema de Estudios de Posgrado, Universidad de Costa Rica.

PNUD. (2001). El desarrollo humano. En línea: hitp://www.pnued.org.vel IDH90/capl.himl

PNUD. (2002). Informe sobre desarrollo humano 2002. Profundizar la democracia en un mundo fragmentado. New York: Ediciones Mundi-Prensa 2002.

Statt, D. (1980). La psicología. Edición Revisada. México: Editorial Harla.

TRIPOD. (2001). Psicología del desarrollo: ¿qué es el desarrollo humano? En línea: http://members.tripod.com/psicol_deshumanoldefinicion.html 